OPEN ACCESS

Edited by:

Sasha Raoul Xola Dall,

University of Exeter, UK

Reviewed by:

Mark Briffa

Plymouth University, UK

Pete Biro,

Deakin University, Australia

*Correspondence:

Pierre-Olivier Montiglio, montiglio.pierre-olivier@ courrier.uqam.ca

Specialty section:

This article was submitted to Behavioral and Evolutionary Ecology,

a section of the journal

Frontiers in Ecology and Evolution

Received: 02 July 2015

Accepted: 08 September 2015

Published: 22 September 2015

Citation:

DiRienzo N and Montiglio P-O (2015)

Corrigendum: Four ways in which data-free papers on animal personality

fail to be impactful.

Front. Ecol. Evol. 3:108.

doi: 10.3389/fevo.2015.00108

\section{Corrigendum: Four ways in which data-free papers on animal personality fail to be impactful}

\author{
Nicholas DiRienzo ${ }^{1}$ and Pierre-Olivier Montiglio ${ }^{2 *}$ \\ ${ }^{1}$ Neurobiology, Physiology and Behavior, University of California, Davis, Davis, CA, USA, ${ }^{2}$ Environmental Science and Policy, \\ University of California, Davis, Davis, CA, USA
}

Keywords: animal personality, behavioral variation, ecology, behavior, mixed models, evolution

\section{A corrigendum on}

Four ways in which data-free papers on animal personality fail to be impactful by DiRienzo, N., and Montiglio, P.-O. (2015). Front. Ecol. Evol. 3:23. doi: 10.3389/fevo.2015.00023

Three of the references we cited in our paper, Biro et al. (2010), Biro (2012), and Stamps et al. (2012) contain an empirical analysis. Hence they are not "data-free."

The corrected section entitled "Methodological Prescriptions" should read as follows. This new version arises from discussions that took place since the publication of the initial article and during the review process:

Some conceptual papers have presented statistical methods, ranging from less powerful but intuitive to more robust but more complex ones. For example, some papers have presented simple ways to quantify intra-individual variability (Stamps et al., 2012; note that this papers does include two empirical examples used to illustrate the method). This statistical approach is intuitive, and its presentation probably motivated further empirical developments on the implications and evolution of intra-individual variability. However, it has the common caveat of doing "stats on stats," and more robust methods are available. In particular, mixed model approaches have been extended to account for or quantify intra-individual variability (Cleasby et al., 2015), or even to assess its underlying mechanisms (Pinheiro and Bates, 2000). Research on animal personality appears to struggle in striking a balance between such intuitive and sophisticated methods, and sophisticated methods might also run the risk of obscuring the biological questions considered in this research area. However, as research questions on animal personality progress, we think that more robust and powerful mixed modeling approaches will be increasingly required.

The above paragraph replaces the previous text as follows:

A number of data-free papers have presented statistical methods, often developed by nonstatisticians. As a result they are usually less powerful. Often these methods appear redundant because a more powerful counterpart is available. For example, mixed models have been extended to account or quantify intra-individual variability more than a decade ago (Pinheiro and Bates, 2000). Yet several data-free papers have been published to present new and less intuitive ways to quantify intra-individual variability (Stamps et al., 2012). Studying animal personality requires quantifying variation at multiple levels, and most often this will require using a mixed modeling approach. This approach is now the default in the field, and we do not need another data-free paper emphasizing its importance or developing a work-around to avoid using it. At this point, the newer generation of researchers (to which we belong) even considers mixed models as a 
basic statistical approach. On related note, arguments can be made against a narrow subset of papers arguing the necessity of additional methodological rigor in empirical studies of animal personality (Biro et al., 2010; Biro, 2012; Niemelä and Dingemanse, 2014). Indeed we do need more rigorous

\section{References}

Biro, P. (2012). Do rapid assays predict repeatability in labile (behavioural) traits? Anim. Behav. 83, 1295-1300. doi: 10.1016/j.anbehav.2012. 01.036

Biro, P. A., Beckmann, C., and Stamps, J. A. (2010). Small within-day increases in temperature affects boldness and alters personality in coral reef fish. Proc. R. Soc. B Biol. Sci. 277, 71-77. doi: 10.1098/rspb. 2009.1346

Cleasby, I. R., Nakagawa, S., and Schielzeth, H. (2015). Quantifying the predictability of behaviour: statistical approaches for the study of betweenindividual variation in the within-individual variance. Meth. Ecol. Evol. 6, 27-37. doi: 10.1111/2041-210X.12281

Niemelä, P. T., and Dingemanse, N. J. (2014). Artificial environments and the study of "adaptive" personalities. Trends Ecol. Evol. 29, 245-247. doi: 10.1016/j.tree.2014.02.007 empirical work, but this should be addressed by producing more exemplary empirical studies, not by arguing in favor of those.

The original article has been updated.

Pinheiro, J., and Bates, D. (2000). Mixed-Effect Models in S and S-PLUS. New York, NY: Springer.

Stamps, J. A., Briffa, M., and Biro, P. A. (2012). Unpredictable animals: individual differences in intra-individual variability (IIV). Anim. Behav. 83, 1325-1334. doi: 10.1016/j.anbehav.2012.02.017

Conflict of Interest Statement: The authors declare that the research was conducted in the absence of any commercial or financial relationships that could be construed as a potential conflict of interest.

Copyright (C) 2015 DiRienzo and Montiglio. This is an open-access article distributed under the terms of the Creative Commons Attribution License (CC BY). The use, distribution or reproduction in other forums is permitted, provided the original author(s) or licensor are credited and that the original publication in this journal is cited, in accordance with accepted academic practice. No use, distribution or reproduction is permitted which does not comply with these terms. 